\title{
Influence of Alloy Elements on the Osteoconductivity of Anodized Ti-29Nb-13Ta-4.6Zr Alloy
}

\author{
Dai Yamamoto ${ }^{1}$, Atsushi Waki ${ }^{1}$, Kensuke Kuroda ${ }^{2}$, Ryoichi Ichino ${ }^{2}$, Masazumi Okido ${ }^{2}$, Masato Ueda ${ }^{3}$, \\ Masahiko Ikeda ${ }^{3}$, Mitsuo Niinomi ${ }^{4}$, Azusa Seki ${ }^{5}$ \\ ${ }^{1}$ Department of Materials Science \& Engineering, Graduate School of Engineering, Nagoya University, Nagoya, Japan; ${ }^{2}$ EcoTopia \\ Science Institute, Nagoya University, Nagoya, Japan; ${ }^{3}$ Faculty of Chemistry, Materials and Bioengineering, Kansai University, Suita \\ Japan; ${ }^{4}$ Institute for Materials Research, Tohoku University, Sendai, Japan; ${ }^{5}$ Hamri Co., Ltd., Tokyo, Japan. \\ Email: yamamoto@f2.numse.nagoya-u.ac.jp
}

Received March 31 $1^{\text {st }}, 2013$; revised May 20 ${ }^{\text {th }}, 2013$; accepted June $6^{\text {th }}, 2013$

Copyright (C) 2013 Dai Yamamoto et al. This is an open access article distributed under the Creative Commons Attribution License, which permits unrestricted use, distribution, and reproduction in any medium, provided the original work is properly cited.

\begin{abstract}
Anodizing is expected to be an effective method to improve the osteoconductivity of the Ti-29Nb-13Ta-4.6Zr (TNTZ) alloy because the bioactivity of anodized $\mathrm{Ti}$ is good. However, it is not known how the alloy elements influence the surface roughness, composition, hydrophilicity, and osteoconductivity of the anodized film on the Ti alloy. In this study, we investigated the effects of anodizing on the surface properties and the osteoconductivity of the anodized TNTZ alloy, focusing on the functions of the individual alloy elements. The anodized oxides of the $\mathrm{Nb}, \mathrm{Ta}$, and $\mathrm{Zr}$ metals were hydrophobic at all the voltages applied, in contrast to the anodized oxide of $\mathrm{Ti}$. As well as pure $\mathrm{Ti}$, a $\mathrm{TiO}_{2}$-based oxide film formed on TNTZ after anodizing. However, the oxide film also contained large amounts of $\mathrm{Nb}$ species and the molar Nb/Ti ratio in the TNTZ alloy was high, which makes the surface more hydrophobic than the anodized oxide on Ti. In vivo tests showed that the osteoconductivity of the TNTZ alloy was sensitive to both its surface roughness and hydrophilicity. When the TNTZ alloy was anodized, the process increased either the surface hydrophobicity or the surface roughness at the voltage used in this study. These changes in the surface properties did not improve its osteoconductivity.
\end{abstract}

Keywords: Ti-29Nb-13Ta-4.6Zr; Anodizing; Titanium Dioxide; Alloy Element; Hydrophilicity; Osteoconductivity

\section{Introduction}

A new single $\beta$ type $\mathrm{Ti}$ alloy, Ti-29Nb-13Ta-4.6Zr (TNTZ), has been developed for biomedical applications $[1,2]$. Because this alloy has a lower Young's modulus than pure $\mathrm{Ti}$ or conventional $\mathrm{Ti}$ alloys, such as the Ti$6 \mathrm{Al}-4 \mathrm{~V}$ alloy, the use of this alloy as a bone substitute is expected to suppress the bone resorption caused by the stress shielding effect, which arises when the Young's modulus of the implant material is higher than that of natural bone. However, despite its improved mechanical biocompatibility, the problem remains that the osteoconductivity of TNTZ is as low as that of pure Ti and the Ti$6 \mathrm{Al}-4 \mathrm{~V}$ alloy [3]. Therefore, surface modification is required to change the surface chemical properties of the TNTZ alloy to improve its osteoconductivity.

Hydroxyapatite (HAp) coatings are widely used as a conventional surface modification for pure Ti to improve its osteoconductivity [4-12]. The anodizing process has also been investigated as a chemical surface treatment for pure $\mathrm{Ti}$, and improves the osteoconductivity of $\mathrm{Ti}$ as much as HAp coatings do, by forming a $\mathrm{TiO}_{2}$ film [13, 14]. Previous studies have shown that the chemical properties of $\mathrm{TiO}_{2}$ films, such as the surface roughness $[13,15]$ crystal structure and crystallinity of $\mathrm{TiO}_{2}[13,16,17]$ film thickness $[13,18]$ and hydrophilicity $[14,19,20]$ can differ depending on the anodizing conditions, resulting in different osteoconductivities. In particular, a fine and hydrophilic surface was found to be better for the early fixation of bone onto anodized $\mathrm{TiO}_{2}$ coatings.

However, when we anodized the TNTZ alloy, Nb, Ta, and $\mathrm{Zr}$ are also contained in the oxide coating in addition to $\mathrm{Ti}$ [3] which may disturb the formation of a $\mathrm{TiO}_{2}$ film on the TNTZ alloy. It is unclear how the alloy elements influence the surface roughness, composition, hydrophilicity, and osteoconductivity of the anodized film on the $\mathrm{Ti}$ alloy. Therefore, we investigated the influence of the $\mathrm{Nb}$, $\mathrm{Ta}$, and $\mathrm{Zr}$ species on the surface properties of the anodized TNTZ alloy in an aqueous solution of $\mathrm{H}_{2} \mathrm{SO}_{4}$, by 
comparing the component metals of the TNTZ alloy. The osteoconductivity of the anodized films on the TNTZ alloy was then evaluated in in vivo tests.

\section{Materials and Methods}

\subsection{Preparation of Substrates}

Disks (surface area of $\left.1.13 \mathrm{~cm}^{2}\right)$ and rods $(2 \times 5 \mathrm{~mm}$ ) of TNTZ alloy were used as substrates to prepare anodized films for their surface analysis and for in vivo tests, respectively. Disks $\left(\right.$ area $\left.=0.79 \mathrm{~cm}^{2}\right)$ of single metals $(\mathrm{cp}-$ $\mathrm{Ti}, \mathrm{Nb}, \mathrm{Ta}$, and $\mathrm{Zr}$ ) and those $\left(\right.$ area $\left.=1.00 \mathrm{~cm}^{2}\right)$ of binary alloys (Ti-35.2Nb [TN], Ti-19.6Ta [TT], and Ti-7.9Zr [TZ], prepared by arc melting), and Ti-6Al-7Nb (Ti67) were used to evaluate the films on the TNTZ alloy in detail. The composition of each binary alloy was controlled to ensure the same $\mathrm{Nb} / \mathrm{Ti}, \mathrm{Ta} / \mathrm{Ti}$, and $\mathrm{Zr} / \mathrm{Ti}$ molar ratios as occur in the TNTZ alloy, as shown in Table 1. All of the substrates were polished with emery paper and then with buffing using $\mathrm{Al}_{2} \mathrm{O}_{3}$ particles (particle size $=$ $0.05 \mu \mathrm{m})$, to produce mirror-finished surfaces $(\mathrm{Ra} / \mu \mathrm{m}<$ 0.1 . After polishing, the substrates were cleaned and degreased with distilled water and ethanol, and then anodized.

\subsection{Anodizing of the Substrates}

A substrate and a Pt coil were set as the anode and cathode, respectively, and no reference electrode was used. Anodizing was performed in a $0.1 \mathrm{M} \mathrm{H}_{2} \mathrm{SO}_{4}$ aqueous solution $(\mathrm{pH}=1.0)$ with an applied voltage that increased from $0 \mathrm{~V}$ up to $200 \mathrm{~V}$ at a rate of $0.1 \mathrm{~V} \cdot \mathrm{s}^{-1}$. After anodizing, the sample was sterilized at $394 \mathrm{~K}$ for a period of $20 \mathrm{~min}$ in an autoclave unit.

\subsection{Analysis of the Coatings}

The surface morphology was examined with scanning electron microscope (SEM). The crystal structures of the anodized films were determined using X-ray diffraction (XRD). The chemical compositions of the anodized films on the surfaces were analyzed using X-ray photoelectron spectroscopy (XPS). The anodized films were etched

Table 1. Molar ratios of $\mathrm{Nb}$, Ta, and $\mathrm{Zr}$ to $\mathrm{Ti}$ in the TNTZ, TN, TT, and TZ alloys.

\begin{tabular}{cccc}
\hline & \multicolumn{4}{c}{ Molar ratio of alloy elements to Ti in the alloy } \\
\cline { 2 - 4 } & $\mathrm{Nb}$ & $\mathrm{Ta}$ & $\mathrm{Zr}$ \\
\hline $\mathrm{TNTZ}$ & 0.280 & 0.064 & 0.045 \\
$\mathrm{TN}$ & 0.280 & - & - \\
$\mathrm{TT}$ & - & 0.064 & - \\
$\mathrm{TZ}$ & - & - & 0.045 \\
\hline
\end{tabular}

with $\mathrm{Ar}$ ion bombardment (at $2 \mathrm{kV}$ ) and depth profiles were obtained using Auger electron spectroscopy. Surface roughness was measured using confocal laser scanning microscope with a measurement area of $150 \times 112$ $\mu \mathrm{m}^{2}$, and expressed with the arithmetical mean of the surface roughness (Ra). The water contact angle (WCA) was measured at three different points for each sample using a $2 \mu \mathrm{L}$ droplet of distilled water after $24 \mathrm{~h}$ in air, and the average value was used as the WCA value.

\subsection{In Vivo Test}

Because the experimental procedure for our in vivo study was almost the same as that described in previous reports [9], it is described only briefly here. Before surgery, all the implants were cleaned in distilled water and immersed in a chlorhexidine gluconate solution. Ten-weekold male Sprague Dawley rats (Charles River Japan, Inc., Tokyo, Japan) were used in our experimental procedures. The specimens were implanted in the tibial metaphysis of the rats. A slightly oversized hole, which did not pass through to the rear side of the bone, was created using a low-speed rotary drill. Subsequently, the implants were inserted into these holes, and then the subcutaneous tissue and skin were closed and sterilized.

The rats were sacrificed after a period of $14 \mathrm{~d}$, and the implants with their surrounding tissue were retrieved. The specimens were fixed in a $10 \%$ neutral buffered formalin solution, dehydrated in a graded series of ethanol, and embedded in methylmethacrylate. Following polymerization, each implant block was sectioned into $20 \mu \mathrm{m}$ thick slices. These sections were then stained with toluidine blue.

The sum of the linear bone contact with the implant surface was measured and was expressed as a percentage over the entire implant length (the bone-implant contact ratio, $\left.R_{\mathrm{B}-\mathrm{I}}\right)$ in the cortical bone part. Significant differences in the bone-implant contact ratio were analyzed statistically using the Tukey-Kramer method [21]. Differences were considered statistically significant at the $p$ $<0.05$ level. This animal study was conducted in the laboratory of the Association for Assessment and Accreditation of Laboratory Animal Care (AAALAC) International.

\section{Results and Discussion}

\subsection{Film Properties}

\subsubsection{Anodizing of Single Metals}

Figures 1-3 show the surface morphology, XRD pattern, and WCA, respectively, of each of the metals at different applied voltages.

The surface of all the metals became rougher as the applied voltage increased (Figure 1). At $\mathrm{Ra} / \mu \mathrm{m}>0.1$, many pores were formed on their surfaces, although the 


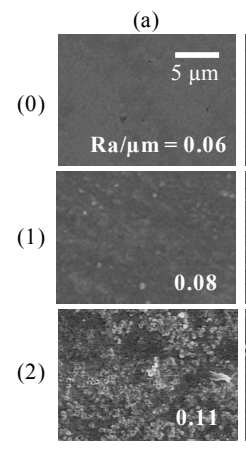

(e)

(0)

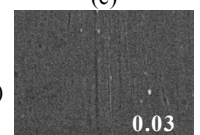

(1)

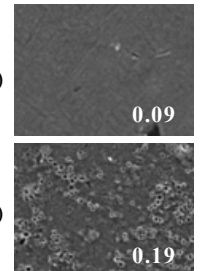

(b)

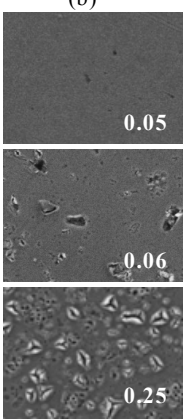

(f)
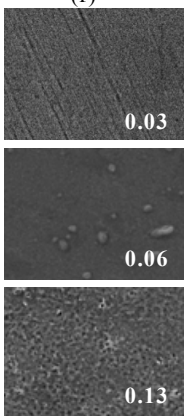

(c)

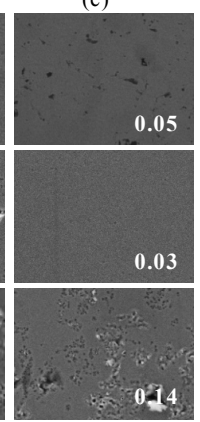

(g)
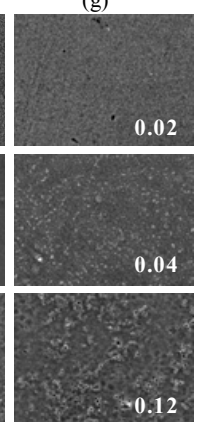

0.12

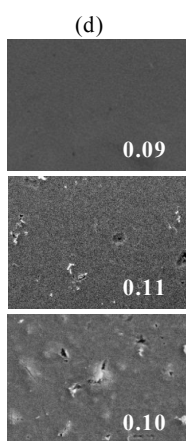

(h)
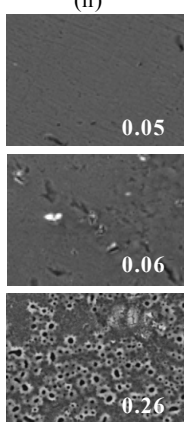

Figure 1. Surface SEM images and surface roughness (Ra) of (a) Ti, (b) Nb, (c) Ta, (d) Zr, (e) TN, (f) TT, (g) TZ, and (h) TNTZ, each of which was (0) as-polished or anodized at a voltage of (1) $100 \mathrm{~V}$ or (2) $200 \mathrm{~V}$ in a $0.1 \mathrm{M} \mathrm{H}_{2} \mathrm{SO}_{4}$ aqueous solution.

degree of roughness differed depending on the type of metal. An oxide film was formed on $\mathrm{Ti}$ as the applied voltage increased. At voltages above $100 \mathrm{~V}$, anatase-type $\mathrm{TiO}_{2}$ was detected in the XRD pattern (Figure 2(a)). The other single metals $(\mathrm{Nb}, \mathrm{Ta}$, and $\mathrm{Zr}$ ) also formed oxide films as the applied voltage increased: $\mathrm{ZrO}_{2}$ was detected on anodized $\mathrm{Zr}$ at voltages above $100 \mathrm{~V}$ (Figure 2(d)), and $\mathrm{Nb}_{2} \mathrm{O}_{5}$ on anodized $\mathrm{Nb}$ at a voltage of $200 \mathrm{~V}$ (Figure 2(b)), but no oxide peak was detected on anodized Ta at any voltage (Figure 2(c)). Because the oxide is in an
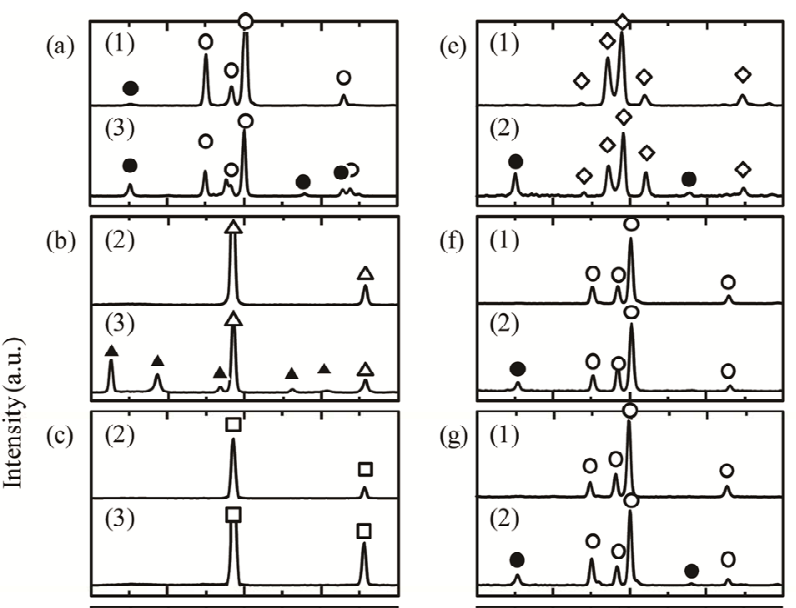

(d)

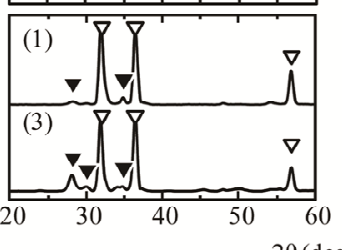

(h) (1)

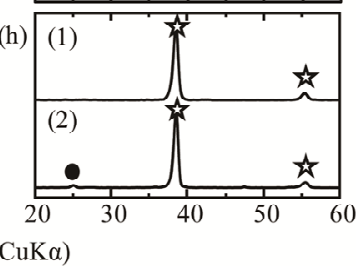

Figure 2. XRD patterns of (a) $\mathrm{Ti}$, (b) $\mathrm{Nb}$, (c) $\mathrm{Ta}$, (d) $\mathrm{Zr}$, (e) TN, (f) TT, (g) TZ, and (h) TNTZ, each of which was anodized at a voltage of (1) $100 \mathrm{~V}$, (2) $150 \mathrm{~V}$, or (3) $200 \mathrm{~V}$ in a $0.1 \mathrm{M} \mathrm{H}_{2} \mathrm{SO}_{4}$ aqueous solution. Symbols: $\odot=\alpha$ - $\mathrm{Ti}, \bar{\tau}=\beta$ - $\mathrm{Ti}$, $\triangle=\mathrm{Nb}, \square=\mathrm{Ta}, \nabla=\mathrm{Zr}, \diamond=\mathrm{Ti}_{4} \mathrm{Nb}, \bullet=\mathrm{TiO}_{2}$ (anatase), $\Delta$ $=\mathrm{Nb}_{2} \mathrm{O}_{5}$, and $\nabla=\mathrm{ZrO}_{2}$.

amorphous form in the first stage of the anodizing of these metals, anodized films that do not have oxide peaks in the XRD pattern are considered to consist of amorphous oxides [22,23].

All the as-polished metals showed similarly high WCA in the rage of $50-70$ (deg.) $(\circ \square \triangle \nabla$ at $0 \mathrm{~V}$ in (a)). When Ti was anodized, the WCA decreased to less than 30 (deg.) at $100 \mathrm{~V}$, and decreased further at above $150 \mathrm{~V}$ ( $\mathrm{O}$ in Figure 3(a)). This is consistent with the previous report that stated that roughness reduces the WCA
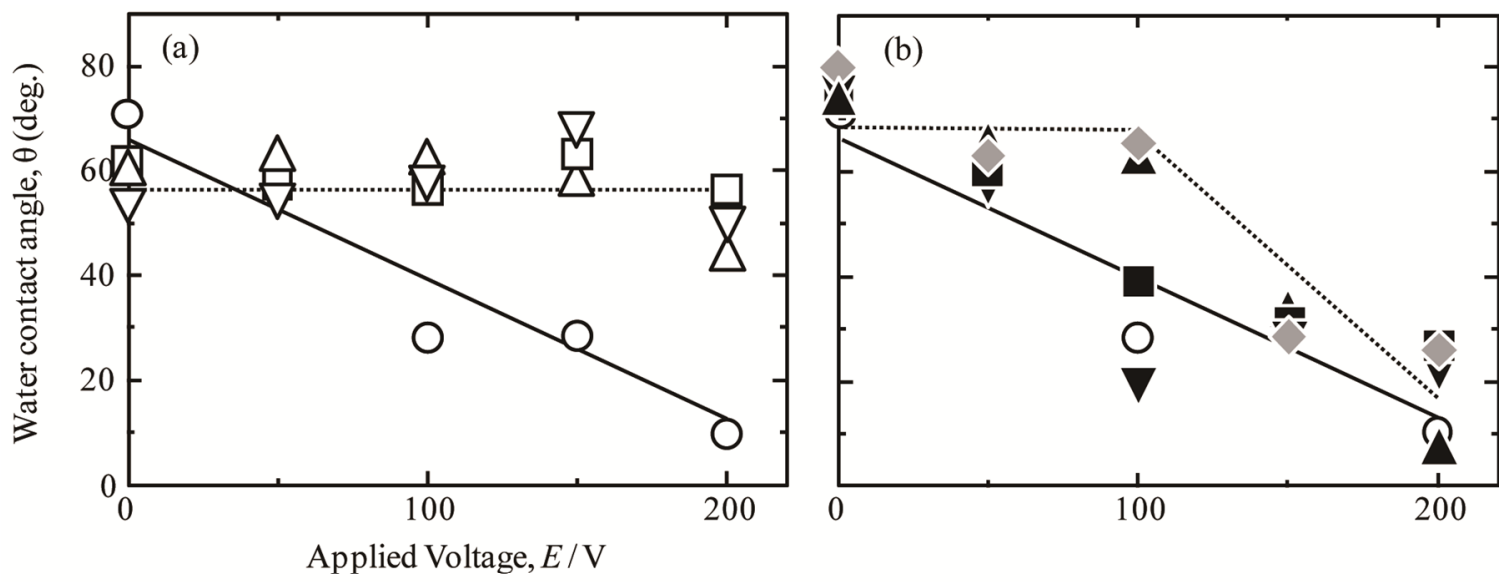

Figure 3. Relationships between WCA and anodizing voltage applied to (a) single metals and (b) Ti-based alloys in a 0.1 M $\mathrm{H}_{2} \mathrm{SO}_{4}$ aqueous solution. Symbols: $\odot=\mathrm{Ti}, \triangle=\mathrm{Nb}, \square=\mathrm{Ta}, \nabla=\mathrm{Zr}, \Delta=\mathrm{TN}, \boldsymbol{a}=\mathrm{TT}, \boldsymbol{\nabla}=\mathrm{TZ}$, and $\diamond=\mathrm{TNTZ}$. 
if its value on the unroughened surface of the same material is $<90$ (deg.) [24]. However, the WCA of the other single metals did not change with increasing surface roughness, but maintained high values of $\geq 50$ (deg.) ( $\triangle$, $\square, \nabla$ in (a)). This indicates that the anodized oxides of $\mathrm{Nb}, \mathrm{Ta}$, and $\mathrm{Zr}$ show low compatibility with water, which cancels the effect of surface roughness.

Surface hydrophilicity is often related to surface $\mathrm{OH}$ groups and adsorbed hydrocarbons. Figure 4 shows the quantitative relationship between these chemical species and WCA. Analysis of the spectrum was performed as in our previous report [14]. In this figure, the amounts of $\mathrm{OH}$ groups and adsorbed hydrocarbons are normalized as ratios to $\left[\mathrm{O}^{2-}\right]$, because the peak intensity can be affected by the vacuum conditions during the analysis. The samples shown in this figure were limited to those with $\mathrm{Ra} /$ $\mu \mathrm{m}<0.1$ to exclude any morphological influence on WCA. Whichever metal was used, the amounts of $\mathrm{OH}$ groups and adsorbed hydrocarbons varied as the applied voltage changed. In particular, the use of different types of metals produced very different values for $[-\mathrm{OH}] /\left[\mathrm{O}^{2-}\right]$ or $[\mathrm{C}-\mathrm{H}] /\left[\mathrm{O}^{2-}\right]$. This means that each of the anodized metals, or more precisely the anodized oxides, had different potential to bind $\mathrm{OH}$ groups or adsorb hydrocarbons on its surface. In contrast, the WCA of anodized $\mathrm{Zr}$ was much higher than that of anodized $\mathrm{Ti}$, even with lower $[\mathrm{C}-\mathrm{H}] /\left[\mathrm{O}^{2-}\right]$ and similar $[-\mathrm{OH}] /\left[\mathrm{O}^{2-}\right]$. This indicates that the effects of the $\mathrm{OH}$ groups or adsorbed hydrocarbons on hydrophilicity differed, depending on the type of underlying oxide. Therefore, the hydrophilicity of different types of oxides cannot be explained simply by the values for $[-\mathrm{OH}] /\left[\mathrm{O}^{2-}\right]$ or $[\mathrm{C}-\mathrm{H}] /\left[\mathrm{O}^{2-}\right]$, and the influence of the underlying oxides must also be considered. However, it was not clear in this study.

\subsubsection{Anodizing Ti Alloys}

Oxide films were formed on all of the binary alloys and the TNTZ alloy after anodizing. At voltages lower than $100 \mathrm{~V}$, no oxide peaks were detected for those alloys with XRD (Figures 2(e) (1), (f) (1), (g) (1) and (h) (1)). The surfaces of these samples were fine $(\mathrm{Ra} / \mu \mathrm{m}<0.1)$ (Figures 1(e) (1), (f) (1), (g) (1) and (h) (1)). At voltages above $150 \mathrm{~V}$, anatase was detected on all of the alloys (Figures 2(e) (2), (f) (2), (g) (2) and (h) (2)) and their surfaces were roughened by surface pores (Figures 1(e) (2), (f) (2), (g) (2) and (h) (2)). No oxides of Nb, Ta, or $\mathrm{Zr}$ species were detected with XRD, even after the highest voltage of $200 \mathrm{~V}$ was applied (Figures 2(e) (2), (f) (2), (g) (2) and (h) (2)). However, the depth profiles revealed that an $\mathrm{Nb}$ species was present in the anodized film on the TN and TNTZ alloys (Figure 5(c) (2)). The chemical composition of the anodized film seemed to re-
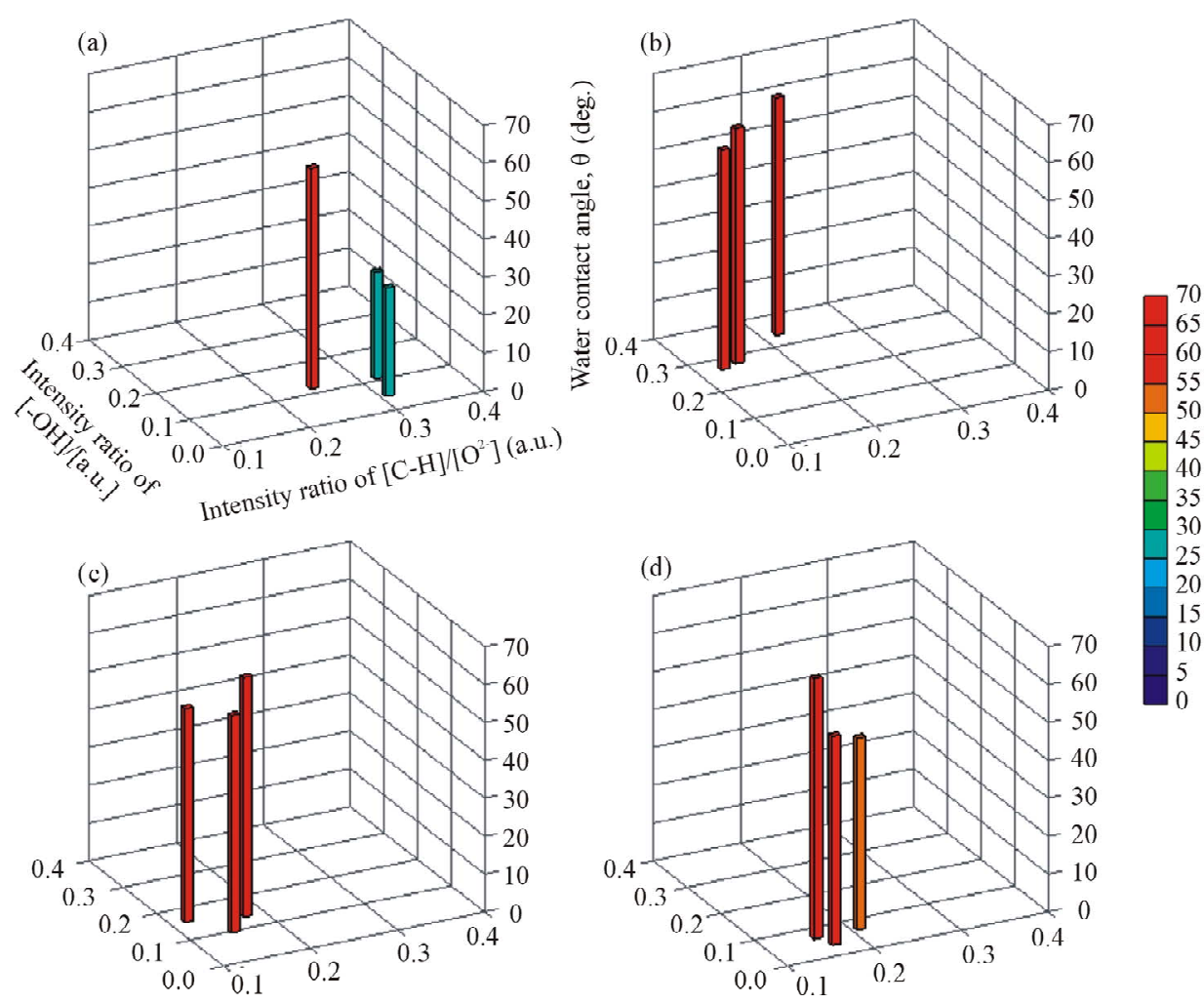

Figure 4. Quantitative relationships among surface $\mathrm{OH}$ groups, adsorbed hydrocarbons, and WCAs for single metals, (a) Ti, (b) $\mathrm{Nb}$, (c) $\mathrm{Ta}$, and (d) $\mathrm{Zr}$, that were anodized at a voltage of 50,100 , or $150 \mathrm{~V}$ in a $0.1 \mathrm{M}_{2} \mathrm{SO}_{4}$ aqueous solution. The amounts of $[-\mathrm{OH}]$ and $\left[\mathrm{O}^{2-}\right]$ were calculated from the O1s spectra of the XPS analysis, and of $[\mathrm{C}-\mathrm{H}]$ from the $\mathrm{C} 1 \mathrm{~s}$ spectra. 
main constant at any applied voltage below $150 \mathrm{~V}$, because the $\mathrm{Nb} / \mathrm{Ti}$ ratio in the film was constant with depth. $\mathrm{The} \mathrm{Nb} / \mathrm{Ti}$ ratio in the anodized films did not change when $0.1 \mathrm{M} \mathrm{H}_{3} \mathrm{PO}_{4}$ was used instead of $0.1 \mathrm{M} \mathrm{H}_{2} \mathrm{SO}_{4}$ for anodizing, as in our previous study [3]. However, little $\mathrm{Ta}$ or $\mathrm{Zr}$ species were present near the surface of the anodized TT or TZ, respectively (Figures 5(d) (2) and (e) (2)). This means that the surface compositions of the anodized TT and TZ alloys were similar to that of anodized pure Ti, unlike those of the anodized TN and TNTZ alloys.

There was no difference in WCA among the Ti alloys before anodizing, but in the samples with $\mathrm{Ra} / \mu \mathrm{m}<0.1$, a difference was clearly seen after anodizing, depending on the type of alloy examined. The WCA of the TT and TZ alloys decreased to 20 - 40 (deg.) after a voltage of $100 \mathrm{~V}$ was applied, in the same way that the WCA of pure Ti decreased. This also indicates that whether the oxide was amorphous or anatase did not influence the WCA. However, the WCA of the TN and TNTZ alloys, which contained $\mathrm{Nb}$ species in the oxides, remained at about 60 (deg.) after the same voltage was applied.

To understand the effect of $\mathrm{Nb}$ on surface hydrophilicity, Ti67, which also contains $\mathrm{Nb}$ as an alloy component, was anodized in $0.1 \mathrm{M} \mathrm{H}_{2} \mathrm{SO}_{4}$ with $100 \mathrm{~V}$ and formed an oxide film with a fine surface $(\mathrm{Ra} / \mu \mathrm{m}<0.1)$. The oxide contained $\mathrm{Nb}$ species, but was hydrophilic, with a WCA of 20 (deg.), unlike the TN and TNTZ alloys. The content of the $\mathrm{Nb}$ species in the oxide film was evaluated, as shown in Table 2 . The $\mathrm{Nb} / \mathrm{Ti}$ ratio in the anodized film was much lower for the Ti67 alloy than
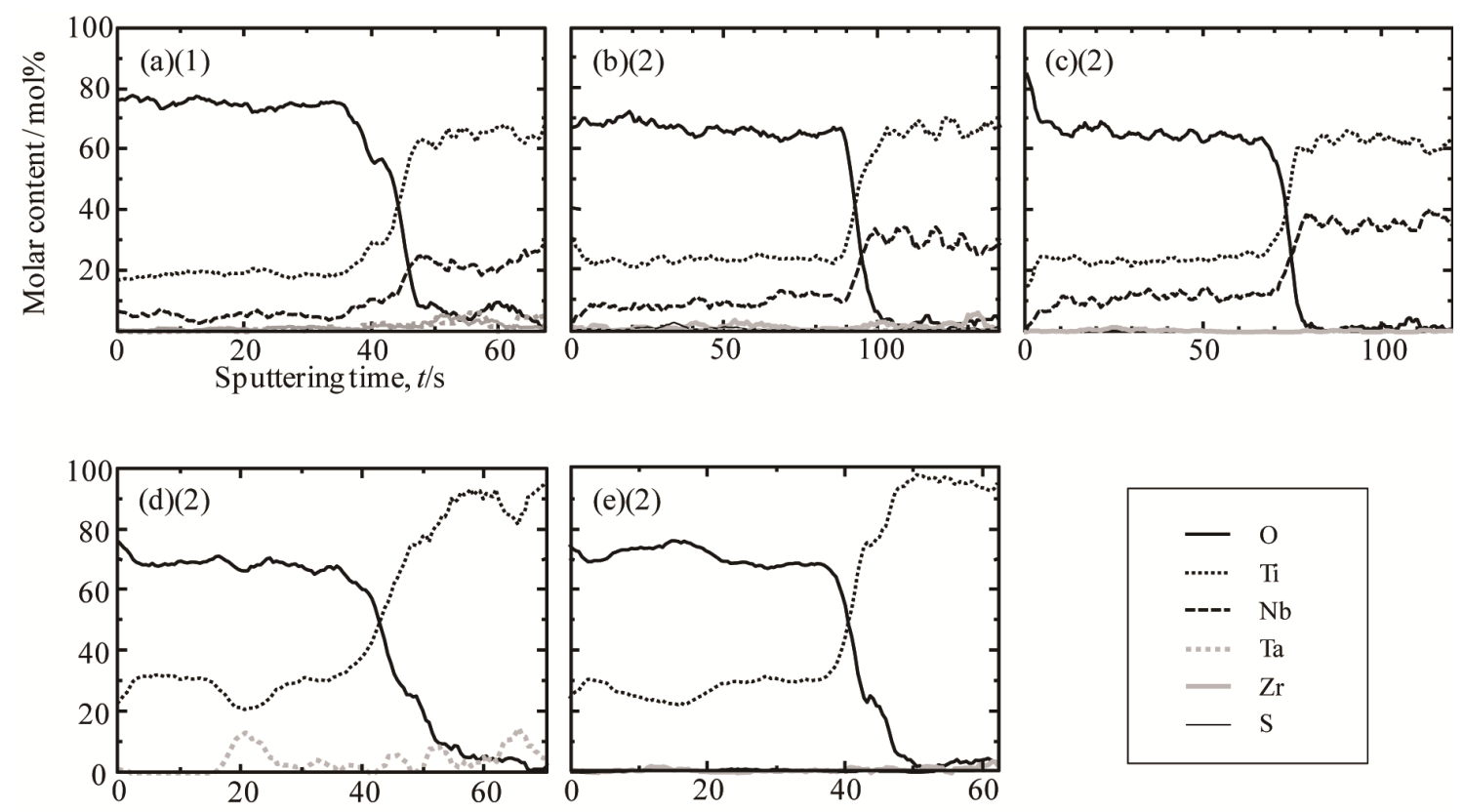

Figure 5. Depth profiles of (a) (b) TNTZ, (c) TN, (d) TT, and (e) TZ, each of which was anodized at a voltage of (1) $100 \mathrm{~V}$ or (2) $150 \mathrm{~V}$ in a $0.1 \mathrm{M} \mathrm{H}_{2} \mathrm{SO}_{4}$ aqueous solution.

Table 2. Average molar ratios of $\mathrm{Nb}, \mathrm{Ta}, \mathrm{Zr}$, and $\mathrm{Al}$ to $\mathrm{Ti}$ in the anodized films and in the substrates TNTZ, TN, TT, TZ, and Ti67, estimated from depth profiles.

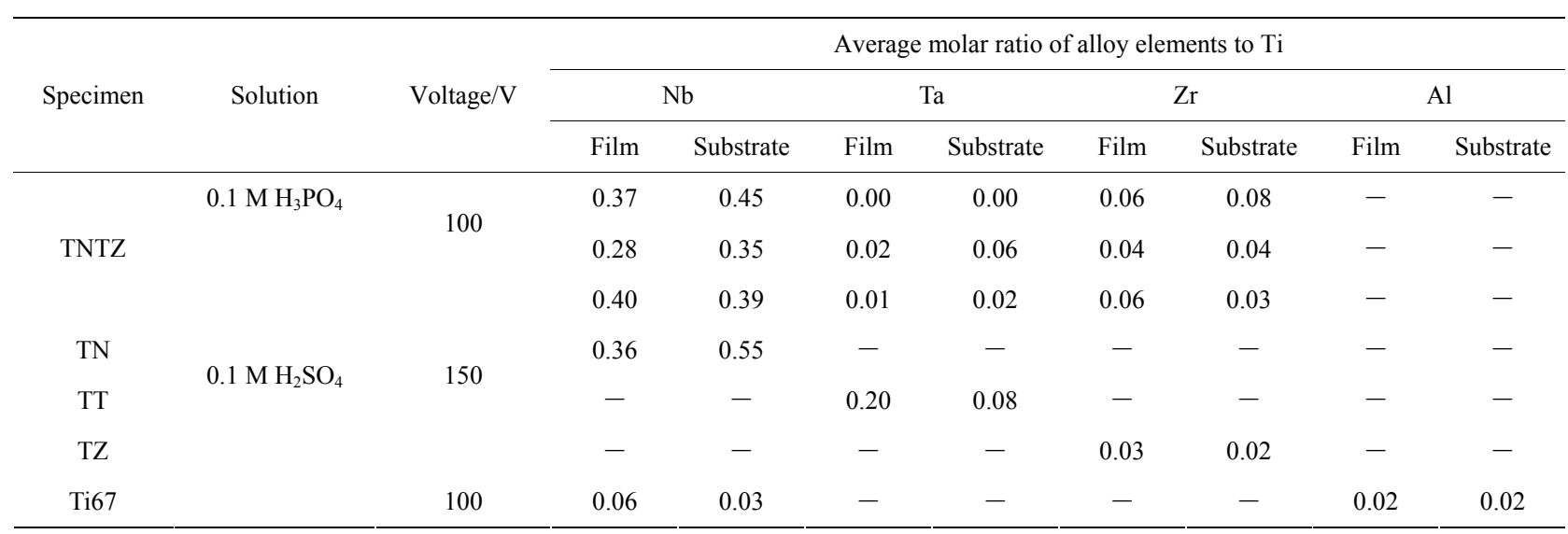


for the TN and TNTZ alloys. Because at least $20 \%$ of Nb ions are reported to be soluble in $\mathrm{TiO}_{2}$ [25], it is thought that $\mathrm{Nb}_{2} \mathrm{O}_{5}$ dissolves into $\mathrm{TiO}_{2}$ to some degree and forms a solid solution, but comes to exist as a second phase when the oxide contains high amount of $\mathrm{Nb}$ species. The second phase of $\mathrm{Nb}_{2} \mathrm{O}_{5}$ seems to have increased the WCA, when the high WCA of anodized $\mathrm{Nb}$ is increased ( $\triangle$ in Figure 3(a)). Similar effects may possibly be caused by $\mathrm{Ta}$ and $\mathrm{Zr}$ if their concentrations are high in the anodized film, but this was not confirmed in this study.

At surface with $\mathrm{Ra} / \mu \mathrm{m}>0.1$, the WCA of the anodized TN and TNTZ alloys decreased to $\leq 40$ (deg.), as in the other binary alloys. From results described above we conclude that when anodizing is used as a surface treatment for the TNTZ alloy, a low WCA cannot be achieved on a fine surface $(\mathrm{Ra} / \mu \mathrm{m}<0.1)$ but can be achieved on a rough surface $(\mathrm{Ra} / \mu \mathrm{m}>0.1)$. Therefore, the samples for the in vivo tests were prepared under the following conditions: (1) anodizing in $0.1 \mathrm{M} \mathrm{H}_{2} \mathrm{SO}_{4}$ at $100 \mathrm{~V}$, to produce a sample with a fine and nonhydrophilic surface, and (2) anodizing in $0.1 \mathrm{M} \mathrm{H}_{2} \mathrm{SO}_{4}$ at 150 $\mathrm{V}$, to produce a sample with a rough and hydrophilic surface.

\subsection{In Vivo Test}

The $R_{\mathrm{B}-\mathrm{I}}$ values for the anodized TNTZ samples in the cortical bone part are shown as a function of WCA in Figure 6. Our previous results for surface-treated $\mathrm{Ti}$, Ti67, and TNTZ $(\mathrm{Ra} / \mu \mathrm{m}<0.1)$ are also plotted on the figure $[3,14]$. For the sample anodized at $100 \mathrm{~V}$ (Figures 6(a) and (d)), $R_{\mathrm{B}-\mathrm{I}}$ was as low as that for the as-polished sample. This value is consistent with the values for anodized Ti showing the same WCA, which are fitted to the curve in Figure 6. For the sample anodized at $150 \mathrm{~V}$ (Figure 6(b)), $R_{\mathrm{B}-\mathrm{I}}$ was also as low as that for the aspolished sample, but the $R_{\mathrm{B}-\mathrm{I}}$ value was lower than the values for anodized Ti with similar WCA. This is because the increase in surface roughness reduced the hard tissue formation on the sample in the range of $0.1<$ $\mathrm{Ra} / \mu \mathrm{m}<0.3$ [15]. In contrast, WCA of the anodized Ti67 alloy also fitted the curve, as did that of the TNTZ sample anodized at $100 \mathrm{~V}$. This means that the $R_{\mathrm{B}-\mathrm{I}}$ values of these alloys tended to change with WCA, in the same way as for pure $\mathrm{Ti}$, and did not depend on the type of base metal. It is also clear that the surface $\mathrm{Nb}$ species influenced hydrophilicity of the alloy but did not directly negatively affect the formation of hard tissue in the living body. This result supports the proposition that $\mathrm{Nb}$ species are not cytotoxic to osteoblast cells [26]. It is important that the $R_{\mathrm{B}-\mathrm{I}}$ values of different types of alloys treated with different anodizing conditions were simply ordered according to their WCAs, even though their surface compositions were quite different. All these data seems

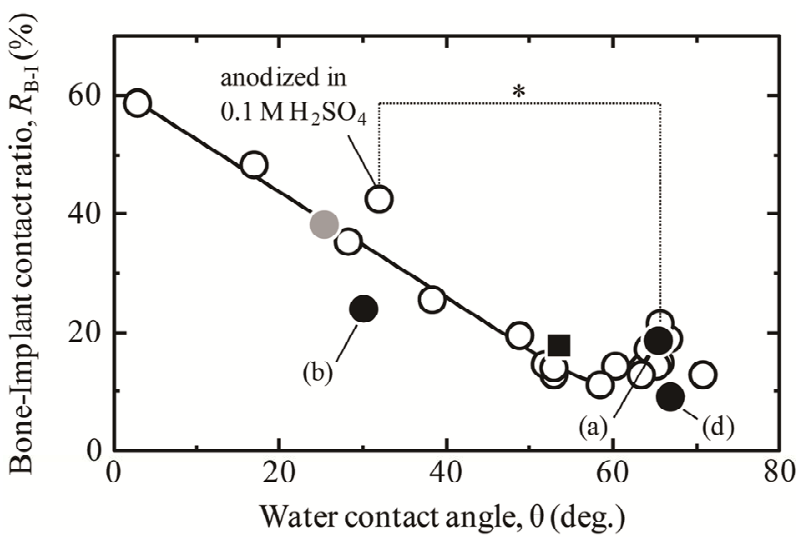

Figure 6. The relationship between WCA and RB-I in the cortical bone part of $\bullet$ : TNTZ specimens anodized in (a) 0.1 $\mathrm{M} \mathrm{H}_{2} \mathrm{SO}_{4}$ solution up to $100 \mathrm{~V}$, (b) $0.1 \mathrm{M} \mathrm{H}_{2} \mathrm{SO}_{4}$ solution up to $150 \mathrm{~V}$, or (d) $0.1 \mathrm{M} \mathrm{H}_{3} \mathrm{PO}_{4}$ solution up to $100 \mathrm{~V}$, $\bullet=\mathrm{Ti67}$ alloy anodized in $0.1 \mathrm{M} \mathrm{H}_{3} \mathrm{PO}_{4}$ solution up to $100 \mathrm{~V}$, n: aspolished TNTZ specimen, and $\odot$ : anatase-coated Ti specimen with the same surface roughness $(\mathrm{Ra} / \mu \mathrm{m}<0.1)$, prepared with different treatments [17]. * $p<0.05$.

to recommend that a hydrophilic surface be fabricated on TNTZ to improve its osteoconductivity, and that is one of goals in our future work.

\section{Conclusions}

In this study, we investigated the influence of the $\mathrm{Nb}, \mathrm{Ta}$, and $\mathrm{Zr}$ species on the surface properties of the TNTZ alloy after its anodizing in an aqueous solution of $\mathrm{H}_{2} \mathrm{SO}_{4}$. We then evaluated the osteoconductivity of the anodized films of the TNTZ alloy in in vivo tests. The following results were obtained:

1) The anodized oxides of the $\mathrm{Nb}, \mathrm{Ta}$, and $\mathrm{Zr}$ metals were hydrophobic at any applied voltage, unlike the single metal Ti.

2) As well as pure $\mathrm{Ti}$, a $\mathrm{TiO}_{2}$-based oxide film formed on TNTZ after anodizing. However, the oxide film also contained high amounts of $\mathrm{Nb}$ species because the molar $\mathrm{Nb} / \mathrm{Ti}$ ratio in the TNTZ alloy substrate is high, and this made the surface more hydrophobic than the anodized oxide on Ti.

3) The in vivo test showed that the osteoconductivity of the TNTZ alloy was sensitive to both surface roughness and hydrophilicity. When the TNTZ alloy was anodized, the process increased either the surface hydrophobicity or the surface roughness at the voltages used in this study. These changes in its surface properties did not improve the osteoconductivity of the TNTZ alloy.

\section{Acknowledgements}

This work was partially supported by a Grant-in-Aid for JSPS fellows (No. 2310401), Project of Advanced Materials Development and Integration of Novel Structured 
Metallic and Inorganic Materials by MEXT, and the Global COE program (COE for Education and Research of Micro-Nano Mechatronics) from JSPS. The authors express their thanks to Daido Steel Co., Ltd. for supplying the TNTZ and Ti67 alloys.

\section{REFERENCES}

[1] M. Niinomi, T. Hattori, K. Morikawa, T. Kasuga, A. Suzuki, H. Fukui and S. Niwa, "Development of Low Rigidity $\beta$-Type Titanium Alloy for Biomedical Applications," Materials Transactions, Vol. 43, No. 12, 2002, pp. 29702977. doi:10.2320/matertrans.43.2970

[2] M. Niinomi, "Mechanical Properties of Biomedical Titanium Alloys," Materials Science and Engineering: A, Vol. 243, No. 1-2, 1998, pp. 231-236. doi:10.1016/S0921-5093(97)00806-X

[3] D. Yamamoto, K. Kuroda, R. Ichino and M. Okido, "Anodic Oxide Coatings on Ti Alloys and Their Osteoconductivity," Materials Science Forum, Vol. 706-709, 2012, pp. 612-616.

doi:10.4028/www.scientific.net/MSF.706-709.612

[4] L. L. Hench and J. Wilson, "An Introduction to Bioceramics," World Scientific, Singapore, 1993. doi: $10.1142 / 2028$

[5] K. Kuroda, R. Ichino, M. Okido and O. Takai, "Hydroxyapatite Coating on Titanium by Thermal Substrate Method in Aqueous Solution," Journal of Biomedical Materials Research Part A, Vol. 59, No. 2, 2002, pp. 390-397. doi:10.1002/jbm. 10002

[6] K. Kuroda, R. Ichino, M. Okido and O. Takai, "Effects of Ion Concentration and $\mathrm{pH}$ on Hydroxyapatite Deposition from Aqueous Solution onto Titanium by the Thermal Substrate Method," Journal of Biomedical Materials Research Part A, Vol. 61, No. 3, 2002, pp. 354-359. doi:10.1002/jbm.10197

[7] K. Kuroda, Y. Miyashita, R. Ichino, M. Okido and O. Takai, "Preparation of Calcium Phosphate Coatings on Titanium Using the Thermal Substrate Method and Their in Vitro Evaluation," Materials Transactions, Vol. 43, No. 12, 2002, pp. 3015-3019. doi:10.2320/matertrans.43.3015

[8] K. Kuroda, S. Nakamoto, R. Ichino, M. Okido and R. M. Pilliar, "Hydroxyapatite Coatings on a 3D Porous Surface Using Thermal Substrate Method," Materials Transactions, Vol. 46, No. 7, 2005, pp. 1633-1635. doi:10.2320/matertrans.46.1633

[9] K. Kuroda, S. Nakamoto, Y. Miyashita, R. Ichino and M Okido, "Osteoinductivity of HAp Films with Different Surface Morphologies Coated by the Thermal Substrate Method in Aqueous Solutions," Materials Transactions, Vol. 47, No. 5, 2006, pp. 1391-1394. doi:10.2320/matertrans.47.1391

[10] K. Kuroda, M. Moriyama, R. Ichino, M. Okido and A. Seki, "Formation and in Vivo Evaluation of Carbonate Apatite and Carbonate Apatite $/ \mathrm{CaCO}_{3}$ Composite Films Using the Thermal Substrate Method in Aqueous Solution," Materials Transactions, Vol. 49, No. 6, 2008, pp. 14341440. doi:10.2320/matertrans.MRA2007330
[11] K. Kuroda, M. Moriyama, R. Ichino, M. Okido and A. Seki, "Formation and Osteoconductivity of Hydroxyapatite/Collagen Composite Films Using a Thermal Substrate Method in Aqueous Solutions," Materials Transactions, Vol. 50, No. 5, 2009, pp. 1190-1195. doi:10.2320/matertrans.MRA2008459

[12] K. Kuroda and M. Okido, "Hydroxyapatite Coating of Titanium Implants Using Hydroprocessing and Evaluation of Their Osteoconductivity," Bioinorganic Chemistry and Applications, Vol. 2012, 2012, Article ID: 730693. doi: $10.1155 / 2012 / 730693$

[13] Y.-T. Sul, C. B. Johansson, S. Petronis, A. Krozer, Y. S. Jeong, A. Wennerberg and T. Albreksson, "Characteristics of the Surface Oxides on Turned and Electrochemically Oxidized Pure Titanium Implants Up to Dielectric Breakdown: The Oxide Thickness, Micropore Configurations, Surface Roughness, Crystal Structure and Chemical Composition," Biomaterials, Vol. 23, No. 2, 2002, pp. 491-501. doi:10.1016/S0142-9612(01)00131-4

[14] D. Yamamoto, T. Iida, K. Arii, K. Kuroda, R. Ichino, M. Okido and A. Seki, "Surface Hydrophilicity and Osteoconductivity of Anodized Ti in Aqueous Solutions with Various Solute Ions," Materials Transactions, Vol. 53, No. 11, 2012, pp. 1956-1961. doi:10.2320/matertrans.M2012082

[15] D. Yamamoto, I. Kawai, K. Kuroda, R. Ichino, M. Okido and A. Seki, "Osteoconductivity of Anodized Titanium with Controlled Micron-Level Surface Roughness," Materials Transactions, Vol. 52, No. 8, 2011, pp. 1650-1654. doi:10.2320/matertrans.M2011049

[16] B. Yang, M. Uchida, H.-M. Kim, X. Zhang and T. Kokubo, "Preparation of Bioactive Titanium Metal via Anodic Oxidation Treatment," Biomaterials, Vol. 25, No. 6, 2004, pp. 1003-1010. doi:10.1016/S0142-9612(03)00626-4

[17] D. Yamamoto, T. Iida, K. Kuroda, R. Ichino M. Okido and A. Seki, "Formation of Amorphous $\mathrm{TiO}_{2}$ Film on Ti Using Anodizing in Concentrated $\mathrm{H}_{3} \mathrm{PO}_{4}$ Aqueous Solution and Its Osteoconductivity," Materials Transactions, Vol. 53, No. 3, 2012, pp. 508-512. doi:10.2320/matertrans.M2011234

[18] C. Larsson, P. Thomsen, J. Lausmaa, M. Rodahl, B. Kasemo and L. E. Ericson, "Bone Response to Surface Modified Titanium Implants: Studies on Electropolished Implants with Different Oxide Thicknesses and Morphology," Biomaterials, Vol. 15, No. 13, 1994, pp. 1062-1074. doi:10.1016/0142-9612(94)90092-2

[19] D. Yamamoto, I. Kawai, K. Kuroda, R. Ichino M. Okido and A. Seki, "Osteoconductivity and Hydrophilicity of $\mathrm{TiO}_{2}$ Coatings on Ti Substrates Prepared by Different Oxidizing Processes," Bioinorganic Chemistry and Applications, Vol. 2012, 2012, Article ID: 495218. doi: $10.1155 / 2012 / 495218$

[20] D. Yamamoto, K. Arii, K. Kuroda, R. Ichino, M. Okido and A. Seki, "Osteoconductivity of Superhydrophilic Anodized $\mathrm{TiO}_{2}$ Coatings on $\mathrm{Ti}$ Treated with Hydrothermal Processes," Journal of Biomaterials and Nanobiotechnology, Vol. 4, No. 1, 2013, pp. 45-52. doi:10.4236/jbnb.2013.41007

[21] C. Y. Kramer, "Extension of Multiple Range Tests to 
Group Means with Unequal Numbers of Replications," Biometrics, Vol. 12, No. 3, 1956, pp. 307-310. doi: $10.2307 / 3001469$

[22] H. Habazaki, M. Uozumi, H. Konno, K. Shimizu, P. Skeldon and G. E. Thopson, "Crystallization of Anodic Titania on Titanium and Its Alloys," Corrosion Science, Vol. 45, No. 9, 2003, pp. 2063-2073. doi:10.1016/S0010-938X(03)00040-4

[23] H. Habazaki, T. Ogasawara, H. Konno, K. Shimizu, S. Nagata, P. Skeldon and G. E. Thompson, "Field Crystallization of Anodic Niobia," Corrosion Science, Vol. 49, No. 2, 2007, pp. 580-593. doi:10.1016/j.corsci.2006.06.005

[24] J. Bico, C. Tordeux and D. Quéré, "Pearl Drops," Euro- physics Letters, Vol. 47, No. 2, 1999, pp. 220-226. doi:10.1209/epl/i1999-00548-y

[25] Y. Furubayashi, T. Hitosugi, Y. Yamamoto, K. Inaba, G. Kinoda, Y. Hirose, T. Shimada and T. Hasegawa, "A Transparent Metal: Nb-Doped Anatase $\mathrm{TiO}_{2}$," Applied Physics Letters, Vol. 86, No. 25, 2005, Article ID: 252101. doi:10.1063/1.1949728

[26] E. Eisenbarth, D. Velten, M. Müller, R. Thull and J. Breme, "Biocompatibility of $\beta$-Stabilizing Elements of Titanium Alloys," Biomaterials, Vol. 25, No. 26, 2004, pp. 5705-5713. doi:10.1016/j.biomaterials.2004.01.021 